\title{
Sleep and Epilepsy Syndromes
}

\author{
Bernhard Schmitt ${ }^{1}$ \\ ${ }^{1}$ Division of Clinical Neurophysiology and Epilepsy, University \\ Children's Hospital, Zurich, Switzerland \\ Neuropediatrics 2015;46:171-180.
}

\begin{abstract}
Address for correspondence Bernhard Schmitt, MD, Division of Clinical Neurophysiology and Epilepsy, University Children's Hospital, Steinwiesstrasse 75, CH-8032, Zurich, Switzerland

(e-mail: bernhard.schmitt@kispi.uzh.ch).
\end{abstract}

\begin{abstract}
Keywords

- sleep

- epileptic encephalopathy

- benign childhood focal epilepsies

- juvenile myoclonic epilepsy

- frontal lobe epilepsy

- parasomnias

Sleep and epilepsy have a close relationship. About $20 \%$ of patients suffer seizures only during the night, approximately $40 \%$ only during the day and approximately $35 \%$ during the day and night. In certain epilepsy syndromes, the occurrence of seizures is strongly related to sleep or awakening. Infantile spasms appear predominately on awakening, and hypsarrhythmia is sometimes visible only in sleep. Children with Panayiotopoulos syndrome or benign epilepsy with centrotemporal spikes (BECTS) have seizures mostly when asleep, and in both syndromes interictal spike waves are markedly accentuated in slow wave sleep. Electrical status epilepticus during slow sleep/continuous spike wave discharges during sleep (ESES/CSWS), atypical benign partial epilepsy, and LandauKleffner syndrome are epileptic encephalopathies with substantial behavioral and cognitive deficits, various seizures, and continuous spike-wave activity during nonrapid eye movement (NREM) sleep. The hallmark of juvenile myoclonic epilepsy and grand mal seizures on awakening are seizure symptoms within 2 hours after awakening, often provoked by sleep deprivation. Nocturnal frontal lobe epilepsy is sometimes mistaken for parasomnia. Differentiation is possible when the clinical symptoms and the frequency of the paroxysmal events per night and month are carefully observed and nocturnal video electroencephalography (EEG) performed. Sleep EEG recordings may be helpful in patients with suspected epilepsy and nonconclusive awake EEG. Depending on the clinical question, sleep recordings should be performed during nap (natural sleep or drug induced), during the night, or after sleep deprivation.
\end{abstract}

\section{Introduction}

Sleep and epilepsy have a reciprocal relationship. On one hand, we have epilepsies with seizures occurring predominately during tiredness, during sleep or on awakening; on the other hand, sleep quality, sleep architecture, and the restorative functions of sleep are compromised by seizures, interictal spike waves (ISWs), and antiepileptic drugs (AEDs). ${ }^{1}$ William R. Gowers has shown, and other authors have confirmed, that approximately $20 \%$ of patients suffer seizures only at night, approximately $40 \%$ only during the day and approximately 35\% during day and

received

December 14, 2014

accepted

April 14, 2015

published online

May 12, 2015 night. Furthermore, ISWs are often activated by sleep, which is why sleep electroencephalography (EEG) should be considered when the wake EEG is not conclusive.

Distinguishing nocturnal seizures from nonepileptic parasomnias can be challenging. A careful clinical history, knowledge of key features of seizure syndromes and parasomnias, and video-EEG monitoring are helpful to avoid misdiagnosis or redundant treatment with AEDs.

This review provides a short overview of sleep-associated epilepsy syndromes. Space limitations only allow the presentation of the most essential aspects. For more details, readers
@ 2015 Georg Thieme Verlag KG
Stuttgart · New York

Neurodevelopmental Disorders; Guest Editor, Oskar G. Jenni, MD
DOI http://dx.doi.org/ 10.1055/s-0035-1551574. ISSN 0174-304X. 
are referred to cited reviews, where they will also find the pioneering literature not cited in this review.

\section{West Syndrome}

West syndrome is characterized by infantile spasms and hypsarrhythmia and usually manifests between 3 and 12 months of age, although earlier or later onsets are not uncommon. The spasms are brief, synchronous, flexor or extensor movements of head, trunk and limbs and typically occur in clusters. The infant often-but not always-utters a brief stereotyped cry immediately after each spasm. Sometimes the spasms are subtle, with series of discrete focal jerks or tonic contractions, facial grimacing, or transient eye deviations. Seizures most commonly occur shortly after awakening, when EEG shows a "relative normalization."2 Thus, it is useful to continue the video-EEG recording for several minutes beyond awakening, particularly when the diagnosis is uncertain or seizures symptoms subtle. Hypsarrhythmia is the pathognomonic EEG feature and is usually apparent awake and asleep but sometimes only appears in sleep. ${ }^{3}$

The most relevant prognostic factor is the etiology, but West syndrome itself may significantly contribute to the developmental outcome. Treatment delay for more than 3 weeks has been shown to have a negative impact on later development. ${ }^{4}$ Earlier studies have indicated that lacking sleep patterns and the severity of hypsarrhythmia have significant prognostic implications. $^{5,6}$ In a recent study, we have shown that hypsarrhythmia, similar to ESES/CSWS, impairs the physiological overnight decrease of slow waves in non-rapid eye movement (NREM) sleep. ${ }^{7}$ Moreover, patients with hypsarrhythmia exhibited steeper slow waves than healthy infants. Slow waves are a marker for synaptic strength, and the overnight reduction of the slow waves is a marker for downscaling this strength, which in turn is a part of the restorative function of sleep and memory consolidation (see the article by Anne-Laure and Huber, Methods in pediatric sleep research and sleep medicine, current issue ).

Treatment should start as soon as possible and the effect should be monitored at short intervals by sleep EEG recordings. According to the recommendations in United Kingdom, ${ }^{8}$ United States of America, ${ }^{9}$ and Germany (www.awmf.org/ leitlinien/detail/1l/022-022.html), the most effective drugs are adrenocorticotropic hormone, high doses of oral steroids (prednisolone), and vigabatrin.

\section{Panayiotopoulos Syndrome}

Panayiotopoulos syndrome is a benign age-related focal epilepsy with onset between age 1 and 14 years (76\% age 3-6 years). ${ }^{10}$ Most seizures (70\%) occur while the child is asleep, $17 \%$ during wakefulness, and $13 \%$ upon awakening. ${ }^{11}$ Seizures often begin with nausea, retching, and vomiting (80-90\%), while consciousness is preserved. Common autonomic symptoms are pallor, flushing, cyanosis, incontinence of urine or feces, hypersalivation, mydriasis or miosis, thermoregulatory alterations, and breathing or cardiac irregularities. ${ }^{10}$ The autonomic symptoms are usually followed by loss of consciousness, eye and head deviation, widely open eyes, speech arrest, hemifacial convulsions, or visual hallucinations. Seizures may end with hemi- or generalized convulsions. Half of the seizures last for more than 30 minutes and often up to many hours, constituting autonomic status epilepticus and often misdiagnosed as encephalitis. ${ }^{10}$ Full recovery after a few hours of sleep is reassuring and can allow the physician to avoid unnecessary investigation. Syncope-like manifestations are common and occur without triggers while standing, sitting, or lying down; they may occur with or without other autonomic symptoms. The affected children are floppy and unresponsive for minutes (up to an hour). Stimulation is ineffective, and recovery is spontaneous and rapid without residual symptoms. ${ }^{12}$

Interictal EEG shows a great variability with multifocal high-amplitude spikes often shifting from one region to another in sequential EEGs of the same child. ${ }^{10}$ Occipital spikes are the most common (76\%), followed by temporal (24\%), parietal (16\%), central (14\%), and frontal (10\%) locations alone or in various combinations. ${ }^{11}$ Sometimes the occipital spikes are "fixation off sensitive" and sleep accentuates ISWs. ${ }^{13}$ Brief generalized discharges of slow waves intermixed with small spikes are occasionally recorded. About $10 \%$ of patients have a normal wake EEG.

Ictal EEG appears before clinical symptoms. The ictal discharges are variable and may start posterior or anterior, unilaterally or bilaterally, usually with theta waves intermixed with small spikes and fast rhythms, spreading to other brain regions. Autonomic manifestations are not related to a specific EEG region. ${ }^{14}$

Prognosis is excellent. Most patients (75\%) have a single or less than five seizures until remission. ${ }^{11}$ However, others may have frequent and prolonged seizures, which are sometimes resistant to treatment. Antiepileptic treatment is not recommended for children with one or brief seizures. Recurrent seizures are often treated with carbamazepine and valproic acid. Rectal diazepam for home administration should be prescribed for prolonged seizures. Remission usually occurs within 1 to 2 years of onset. ${ }^{10}$ After clinical remission, spikes may persist for many years. Neuropsychological testing is usually normal. ${ }^{11}$

\section{Benign Epilepsy with Centrotemporal Spikes}

Benign epilepsy with centrotemporal spike (BECTS), also known as benign rolandic epilepsy, is the most frequent epilepsy in children. ${ }^{15}$ The onset is between 3 and 13 years with remission before the age of 16 years. ${ }^{16}$ Seizure semiology is characterized by hemifacial cloni and lateral tonic deviation of the mouth and tongue with salivary flow. Seizure symptoms are sometimes preceded by paresthesia involving cheek, tongue, and lips. ${ }^{17}$ During the seizure, contact is often preserved, the child is able to understand but unable to speak, and the next day the children often remember the nocturnal seizure precisely. The seizures last from less than a minute to two minutes. Spreading to the homolateral arm and leg or secondary generalization might occur. Lerman ${ }^{15}$ distinguished the following three types of nocturnal seizures: (1) brief hemifacial seizures associated with speech arrest and drooling in a conscious state; (2) hemifacial seizures with loss of consciousness, gurgling-grunting noises, and vomiting after the seizure; and (3) generalized tonic-clonic seizures (GTCS). Seizure frequency is usually low, and approximately $70 \%$ occur during sleep, mainly short after falling asleep or in 
the morning short before awakening. ${ }^{18}$ Treatment (with carbamazepine, valproic acid, gabapentin, levetiracetam, oxcarbazepine, or sulthiame) is only necessary when seizures are frequent or disturbing. ${ }^{19}$ Because the extent of EEG abnormalities does not correlate with the seizure propensity and prognosis, EEG is not suitable for treatment decisions.

Interictal EEG is characterized by high-voltage monomorphic centrotemporal spike waves often diffusing to the adjacent regions. Spike waves are also found midtemporally, centroparietally, frontocentrally, centro-occipitally, or multifocally. They are unifocal or bifocal and appear singly or in groups. When bilateral asynchronous, they have different rates and amplitudes. Spike waves may shift from side to side in consecutive recordings. ${ }^{18,20}$ During drowsiness and sleep, frequency and amplitude increase, with a tendency to shift or spread from side to side. Background activity and physiological sleep pattern are usually normal.

The typical BECTS has no underlying structural brain abnormalities. Therefore, magnetic resonance imaging (MRI) is not necessary when clinical and EEG features are typical. Genetic disposition was found by Doose and Baier, ${ }^{21}$ and recently GRIN2A mutation was detected in some individuals with BECTS. ${ }^{22}$ Children with BECTS have no neurological or intellectual impairment. However, behavioral and neuropsychological problems have been reported and seem to correlate with the presence of an intermittent slow wave focus during wakefulness, a high number of spikes in the first hour of sleep (and during whole night sleep), and multiple asynchronous bilateral spike-wave foci in the first hour of sleep. ${ }^{23}$ Continuous psychological testing during spike-wave discharges revealed brief episodes of impaired cognitive function. ${ }^{24}$ Prognosis is excellent, and the disturbances tend to have normalized by the long-term follow-up.

\section{The Spectrum of Electrical Status Epilepticus during Slow Sleep}

Electrical status epilepticus during slow sleep (ESES) is an EEG pattern characterized by near-continuous spike-wave discharges in slow-wave sleep. The first description was presented by Patry et $\mathrm{al}^{25}$ who found an association of ESES with seizures and cognitive dysfunction. Morikawa et $\mathrm{al}^{26}$ proposed the term "continuous spike-wave discharges during sleep (CSWS)," since "status epilepticus" implied clinical manifestations. In literature, ESES and CSWS are used more or less interchangeably. Other epileptic syndromes characterized by a distinct increase of spike-waves during sleep are atypical benign partial epilepsy or pseudo-Lennox syndrome and Landau-Kleffner syndrome (LKS). These syndromes are variants of ESES/CSWS, and the transitions between them are fluent. Recent genetic data indicate a continuum between BECTS, atypical benign partial epilepsy, ESES/CSWS, and $\mathrm{LKS}^{22,27}$

\section{Electrical Status Epilepticus during slow sleep/ Continuous Spike-Wave Discharges during Sleep}

The Commission on Classification and Terminology of the International League against Epilepsy ${ }^{28}$ gave the following definition of ESES/CSWS:
Epilepsy with continuous spike waves during slow sleep results from the association of various seizure types, partial or generalized, occurring during sleep, and atypical absences when awake. Tonic seizures do not occur. The characteristic EEG pattern consists of continuous diffuse spike waves during slow-wave sleep, which is noted after onset of seizures. Duration varies from months to years. Despite the usually benign evolution of seizures, prognosis is guarded, because of the appearance of neuropsychological disorders.

ESES/CSWS is an age-related epileptic encephalopathy with seizure onset between 2 months and 12 years (peak $2-4$ years). ${ }^{29}$ During the prodromal stage, seizures are unilateral clonic or tonic-clonic and typically occur out of sleep. During ESES, seizure frequency increases and atonic seizures (falls), and atypical absences appear and become increasingly difficult to control. The lack of tonic seizures allows differentiation from Lennox-Gastaut syndrome.

ESES/CSWS is associated with new cognitive deficits and behavioral disturbances regardless of previous cognitive status and development. The regression is either acute or insidious and usually appears some months after the onset of clinical seizure. ${ }^{30}$ Intelligence quotient or developmental quotient decrease, and several behavior and cognitive abnormalities have been reported. ${ }^{29,31}$ The exact incidence of each abnormality is unknown. Attention deficits and hyperactivity are frequently reported. Other cognitive deficits are expressive language disorders (for receptive language disorder see LKS), dyscalculia, dyslexia, global dyspraxia, apraxia, hemineglect, impaired visuo- and temporospatial orientation, short-term memory impairment, and deficits in reasoning. Regarding behavioral abnormalities, aggressiveness, deficits in relatedness and inhibition, encopresis, enuresis, bizarre behavior, emotional lability, psychotic behavior, anxiety, phobias, autistic-like behavior, stereotypies, coprophagia, compulsive hyperorality, depression, strange corporal perception, automutilation, insensitivity to pain, echolalia, and echopraxia are listed in the review by Galanopoulou et al (2000). ${ }^{31}$ Motor deficits with ataxia, dystonia, or dyspraxia may occur and may be unilateral. ${ }^{29}$

EEG during wakefulness shows focal and multifocal spikes that are usually more marked during the acute stage. The characteristic feature of ESES/CSWS is a distinct increase of bilateral high-amplitude 1.5 to 2.5/s slow spike waves as soon as the patient falls asleep ( $\mathbf{- F i g . 1 A , ~ B ) . ~ T h e ~ s p i k e - w a v e ~ i n d e x ~}$ (SWI) ranged from 85 to $100 \%$ during all-night NREM sleep stages. ${ }^{25,29}$ Several methods to determine the SWI have been reported (for a review, see Scheltens-de Boer). ${ }^{33}$ We prefer the method described by Aeby et $\mathrm{al}^{34}$ : the percentage of seconds with $\geq 1$ spike-wave complex during the first 30 minutes of NREM sleep during the first and the last sleep cycle. Although the importance of a high SWI during sleep is agreed on, cutoff values below $85 \%$ are used by other authors. Qualitative parameters such as spike amplitude, morphology, frequency, and distribution during sleep and parameters such as background activity, sleep pattern, and sleep architecture 


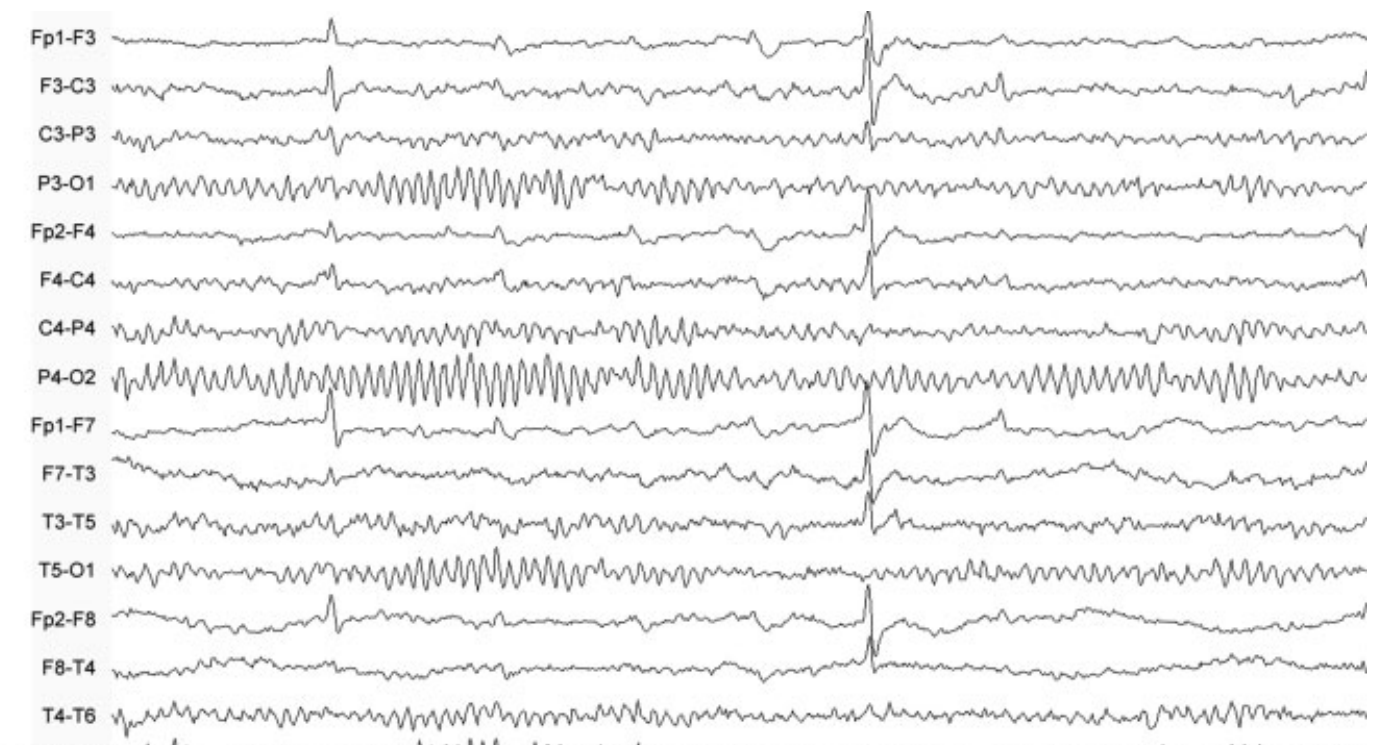

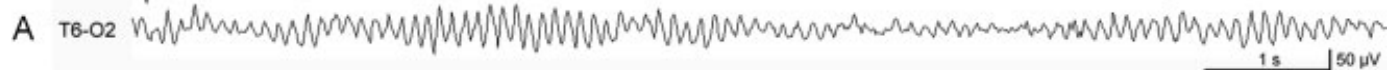

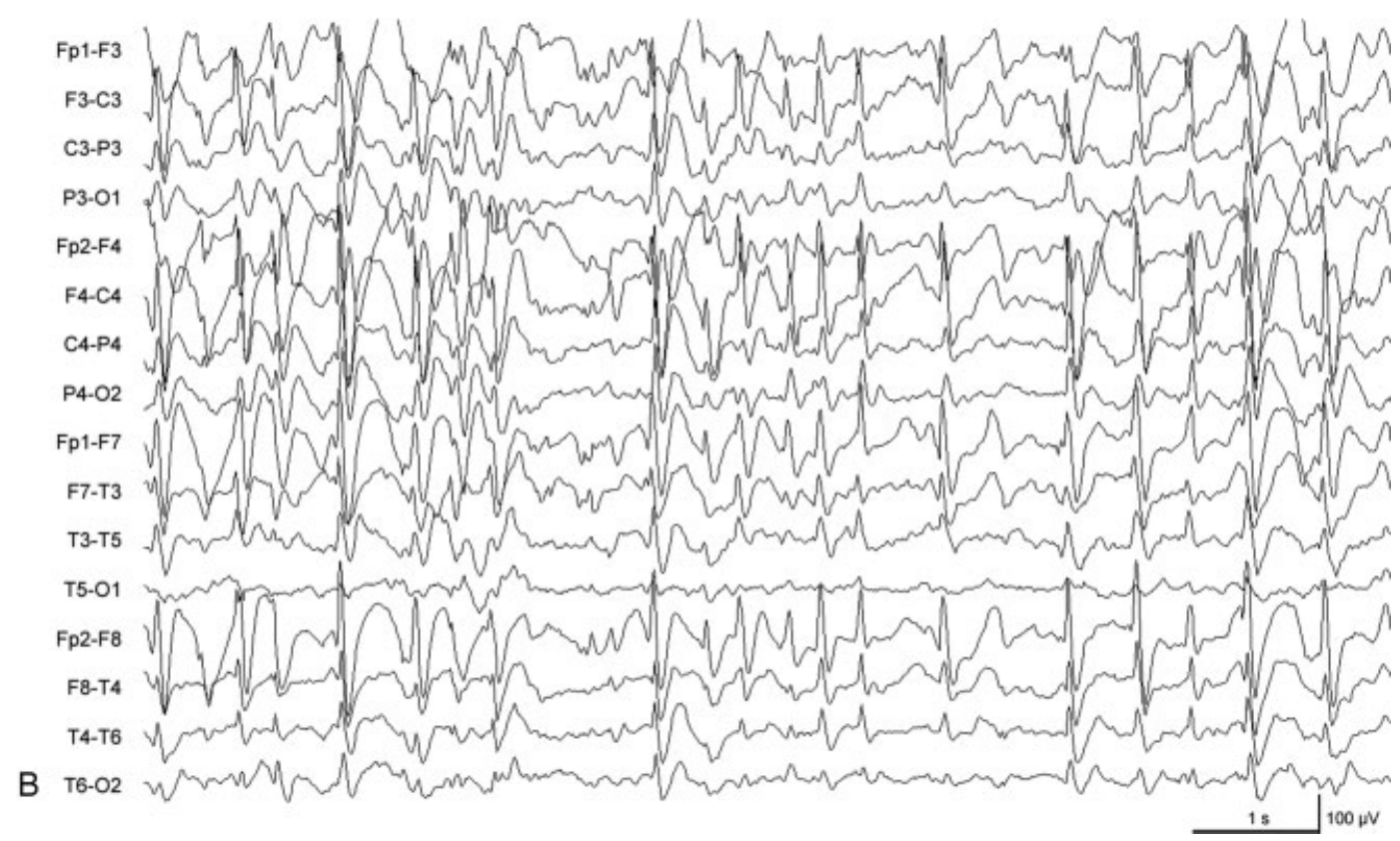

Fig. 1 ESES/CSWS, age 8 years (A) awake: single frontal sharp waves, (B) 10 minutes later asleep: continuous bilateral spike waves in NREM sleep, SWI $>85 \%$. Reprint with permission from Schmitt and Wohlrab. ${ }^{32}$ CSWS, continuous spike-wave discharges during sleep; ESES, electrical status epilepticus during slow sleep; NREM, non-rapid eye movement; SWI, spike-wave index.

might play an important role in determining the severity and prognosis of ESES/CSWS. ${ }^{33}$

About half of the patients with ESES/CSWS have malformations or cortical lesions. ${ }^{31}$ In particular, prenatal or perinatal thalamic injuries are associated with ESES/CSWS. ${ }^{35}$ Recently, GRIN2A mutations have been found in patients with ESES/CSWS, BECTS, and LKS supporting the view of a spectrum disorder with fluent passages between these entities. ${ }^{22,27}$ The pathomechanism behind the emergence of ESES/CSWS is largely unknown. Disturbance of the corticothalamic network and an alteration of the NMDA receptor with respect to the GRIN2A mutation have been discussed. $^{22,27}$ The mechanism responsible for the cognitive deficits is also unknown. Tassinari et $\mathrm{al}^{29}$ hypothesized an interference of spike waves with the physiological slow-wave activity in NREM sleep, resulting in an impairment of brain recovery during the sleep necessary to regain optimal cognitive performance. And indeed, recent data by Bölsterli et $\mathrm{al}^{36,37}$ have shown that the physiological decrease of slow waves during sleep is impaired in patients with ESES/ CSWS, and the decrease is more hampered the higher the SWI is. They also found that, in most patients with SWI $>85 \%$, the physiological slow-wave decrease is completely lost. EEG functional MRI studies during spike waves in slow-wave sleep showed a specific neuronal network of propagation including the perisylvian region, insula, and cingulate gyrus. ${ }^{38}$ This 
activation was associated with deactivations in the default mode network which is prominent in neuropsychological processes and memory consolidation during sleep and might explain the neuropsychological deficits in ESES/CSWS.

Cognitive functioning may improve when spike waves are reduced with AEDs. No controlled clinical trials have been conducted to establish the efficacy of different AEDs, and successful treatment is often difficult to achieve. The primary goal is to improve neuropsychological functions or to prevent cognitive deterioration. Treatment options are steroids, levetiracetam, benzodiazepines, ethosuximide, valproic acid, sulthiame, immunoglobulins, ketogenic diet, and multiple subpial transections. ${ }^{39}$ Because recent data indicate that the cognitive outcome is associated with the duration of CSWS/ESES, ${ }^{40,41}$ aggressive treatment including steroids should be considered.

The long-term outcome of ESES/CSWS is variable and depends on the etiology, the duration of ESES and the treatment response. ${ }^{40,41}$ The behavioral disturbances resolve soon after the EEG has normalized, whereas cognitive functions improve at a slower pace and for a longer time. Nevertheless, permanent cognitive impairments often remain.

\section{Atypical Benign Partial Epilepsy/Pseudo-Lennox Syndrome}

Aicardi and Chevrie ${ }^{42}$ reported seven children who satisfied the criteria for benign partial epilepsy, but their sleep recordings displayed almost continuous slow spike-wave activity. In addition to focal motor seizures, these patients suffered from atypical absences and myoclonic and atonic attacks. Because of the favorable course of the children's condition, they coined the disease atypical benign partial epilepsy. Doose ${ }^{43}$ described patients who were similar but with mental deficit and proposed the term pseudo-Lennox syndrome. Epilepsy onset ranged between age 0.4 and 8.5 years (peak 3.1 years). ${ }^{44}$ EEG features, treatment options, and outcomes are similar to ESES/CSWS. Within the spectrum, atypical benign partial epilepsy is probably positioned between rolandic epilepsy and the ESES/CSWS and LKS continuum.

\section{Landau-Kleffner Syndrome}

In 1957, Landau and Kleffner reported five children with acquired receptive aphasia in association with epilepsy and spike waves in EEG and termed the disease "syndrome of acquired aphasia with convulsive disorder in children," 45 which was later renamed LKS. The syndrome is characterized by (1) acquired aphasia due to auditory agnosia; (2) epilepsy; (3) unilateral or lateralized spike waves, bitemporal or diffuse, with increase during NREM sleep; (4) normal brain imaging; and (5) improvement of language when spike waves disappear. ${ }^{46,47}$ Additional cognitive and behavioral deficits have been reported. The onset is acute or insidious and ranged from ages 2 to 8 years. Before onset, children are normal and have already developed age-appropriate language. Seizures (focal motor seizures with and without secondary generalization, atypical absences) are milder than in ESES/CSWS and mostly easy to treat. In 20 to $30 \%$ of the patients, seizures never occur. The SWI in the nocturnal EEG is often $<85 \%$. The treatment options are similar to those in ESES/CSWS. ${ }^{46,47}$ The epilepsy outcome is good; most patients remain seizure free. The language improves after the spike waves have disappeared, but deficits in language and cognition often persist. Similar to ESES/CSWS, language and cognitive outcomes seem to depend on the duration of the active period of the disease. $^{46}$

\section{Juvenile Myoclonus Epilepsy or Janz Syndrome}

Juvenile myoclonus epilepsy (JME) is characterized by strong chronodependency and association to sleep. Seizures usually appear within 2 hours of awakening, and sleep deprivation is known to be a crucial trigger. Clinical and EEG characteristics were established by Janz and Christian ${ }^{48}$ with the name "impulsive petit mal" and later renamed JME. The hallmark of JME is myoclonic jerks without loss of consciousness, repeatedly occurring after awakening. The jerks are spontaneous, brief, bilateral, single or repetitive, arrhythmic, and irregular and often occur in brief clusters. Upper limbs are predominantly affected and may make the patients to drop or throw objects such as coffee cups or mobile phones. Violent myoclonic jerks may involve the lower limbs, causing a flexion of the knees and falls. In longer series, myoclonic jerks may increase in amplitudes and frequency and pass into GTCSs. They typically occur in the morning after awakening, particularly when the preceding sleep has been insufficient. But they may also occur after a nap or during intermediate or provoked awakenings at night. ${ }^{49}$ According to a consensus meeting in 2011, the occurrence of myoclonic jerks is an obligatory criterion for the diagnosis of JME. ${ }^{50}$ GTCSs are almost exclusively of the awakening type, often subsequent to a cluster of myoclonic jerks. Provoked by insufficient sleep, they are intense and the postictal asthenia prolonged. ${ }^{49}$ Absence seizures occur with a prevalence of 10 to $38 \%$. They are short and infrequent with partial impairment of consciousness and often detected only in long-term EEG recordings. ${ }^{49}$ Other seizures are perioral reflex myoclonia (precipitated by reading, speaking, and other neuropsychological activation) and praxis-induced seizures. ${ }^{51}$ Photosensitivity with myoclonic jerks or GTCS are reported with divergent frequencies, ${ }^{51,52}$ although photoparoxysmal responses in EEG are found in 38\% of the patients.

Diagnosis is made by careful interview of the patient focusing on myoclonic jerks after awakening. The EEG shows polyspike waves with three or more spikes followed by slow waves, 2.5 to $3.5 / \mathrm{s}$ spike waves, $>3.5 / \mathrm{s}$ spike waves and classical 3/s spike waves (for review see the study by Serafini et al). ${ }^{53}$ Focal or asymmetric spike waves occur. Background activity and sleep pattern are normal. Myoclonic jerks are associated with rapid 5 to 20 polyspikes of increasing amplitude with maxima over the frontal region, followed or preceded by high-amplitude 3 to $4 / \mathrm{s}$ slow waves. Perioral reflex myoclonia and praxis-induced seizures coincide with generalized spikes and rapid spike waves. ${ }^{51}$ Normal routine EEG does not exclude the diagnosis of JME. Long-term video- 
EEG in sleep or nocturnal sleep deprivation followed by a short morning nap and subsequent sudden awakening might be helpful. Because sleep deprivation bears the risk of GTCS, $0.5 \mathrm{mg} / \mathrm{kg}$ clobazam is recommended as soon as myoclonic jerks have been recorded. ${ }^{52}$

JME begins between 8 and 26 years of age (peak, 12-18 years) with a female predominance. ${ }^{52} \mathrm{JME}$ is not associated with neurological or mental deterioration, but several studies suggest psychiatric comorbidity and specific cognitive deficits. Schmitz et $\mathrm{al}^{54}$ summarized the deficits as problems in cognitive tasks linked to the frontal lobes with impact on interpersonal relationships and social outcome. However, the majority of patients with JME have no relevant neuropsychological deficits or psychiatric comorbidity.

JME is treatable in most patients. ${ }^{55}$ Valproic acid $(1,000-$ $2,000 \mathrm{mg} / \mathrm{d}$ ) is very effective but is not the first-line treatment in females of child-bearing age or in obese patients. Topiramate is also efficacious but less tolerated and sometimes associated with cognitive adverse effects. Lamotrigine is effective but may aggravate myoclonic jerks. Levetiracetam is not mentioned for JME in an "Updated ILAE evidence review of antiepileptic drug efficacy" ${ }^{19}$ but seems to be another option. Carbamazepine, oxcarbazepine, gabapentin, phenytoin, tiagabine, und vigabatrine may precipitate or aggravate absence seizures, myoclonic seizures, and GTCS. ${ }^{19}$ A lifestyle with regular wake-sleep rhythm is recommended, and patients should know about the risk of seizure recurrence after sleep deprivation and excessive alcohol intake. Because in adolescence regimentations are often difficult to enforce and because excessive regimentation may be counterproductive for normal socialization, the perils of seizures (e.g., drowning in bath, driving) should be expressly communicated.

Lifelong treatment is recommended in most studies. A recent retrospective cohort study in 66 patients with JME and follow-up of 44 years (range, 20-69 years) revealed 11 (28\%) patients who were off medication for at least 5 years. Additional absence seizures at onset of JME seems to be a predictor of an unfavorable outcome regarding seizure freedom. ${ }^{56}$

\section{Grand Mal Seizures on Awakening}

Grand mal seizures on awakening (GMA) is both a separate entity and part of other generalized epilepsies. Similar to JME, GMA have strong chronodependency and occur after awakening or in the late afternoon or evening hours of leisure and relaxation. ${ }^{57}$ In juvenile absence epilepsy, GMA may precede the manifestation of absence seizures, ${ }^{16}$ and in JME GMA is often the reason to seek medical attention. Age of onset of pure GMA is 6 to 35 years. ${ }^{57}$ Although GMA is recognized as a distinct nosological entity by the International League Against Epilepsy, ${ }^{16}$ the debate is ongoing whether GMA is an entity separate from JME. ${ }^{58}$ Both syndromes have similar profiles, with seizures provoked by sleep deprivation, occurrence after awakening, comparable EEG changes, response to similar AED, long treatment re- quirement, and a high relapse rate after AED withdrawal. Even the long-term outcome is in line with the prognosis of JME. 59

\section{Nocturnal Frontal Lobe Epilepsy}

Nocturnal frontal lobe epilepsy (NFLE) manifests at any age but most commonly in childhood (mean, $14 \pm 10$ years). ${ }^{60}$ The diagnosis is sometimes difficult, and symptoms are often mistaken for parasomnia or other nonepileptic sleep disorders. In a clinical and polygraphical overview of 100 consecutive cases, Provini et $\mathrm{al}^{61}$ distinguished the following three subtypes of NFLE:

- Paroxysmal arousal (range, 2-20 seconds): Patients suddenly open their eyes, raise their heads, or sit up in bed with a bizarre dystonic posture of the limbs, show bending or rocking movements, stare around with a frightened or surprised expression, and sometimes scream. After the attack, patients quickly go back to sleep.

- Nocturnal paroxysmal dystonia (20 seconds-2 minutes): Nocturnal paroxysmal dystonia begins with a paroxysmal arousal, followed by wide, often violent motor attacks with complex dystonic-dyskinetic features. Attacks may show the typical pattern of supplementary motor seizures with extension of the ipsilateral limb, flexion of the contralateral limb, and rotation of the head. Other attacks display rhythmic or ballistic movements with kicking, cycling, or body rocking.

- Episodic nocturnal wanderings (range, 1-3 minutes) are characterized by stereotypic, agitated ambulation with suddenly changing directions, jumping, and screaming.

Intraindividual seizures are remarkably stereotypical, although all three NFLE types are sometimes present in the same patient. Almost all seizures occur during NREM sleep, two-thirds in stage 1 to stage 2 and one-third in stage 3 to stage 4 . Seizure frequency is at mean $20 \pm 11$ seizures per months and 1 to 20 (mean $3 \pm 3$ ) per night. Nocturnal secondary generalized seizures with prolonged tonic/vibratory and asymmetric features occur and seizures during the day similar to those during sleep are occasionally reported. The majority of the patients are not aware of their nocturnal motor behavior. Carbamazepine is reported to be effective, but approximately $50 \%$ of the patients are drug refractory. There is no spontaneous remission and always a relapse when AEDs are withdrawn. ${ }^{61}$

Interictal EEG is normal or may show focal epileptic abnormalities awake or asleep. Ictal video-EEG depicts diffuse or focal flattening of the background activity, focal theta or delta activity, and sometimes spike waves over the frontal, frontotemporal, vertex, or temporal region. However, in half of the registered seizures, EEG fails to disclose an ictal pattern. ${ }^{61}$

NFLE with autosomal dominant transmission (ADNFLE) was first described by Scheffer et al. ${ }^{62}$ Meanwhile, several mutations, both in coding for subunits of the nicotinic acetylcholine receptor (CHRNA4) and in other genes (KCNT1 and DEPDC5) have been found. ${ }^{63,64}$ 
A vague relation between NFLE and parasomnia has been discussed and reasoned by a high family history of parasomnias in patients with NFLE and by anamnestic episodes of parasomnia in patients who subsequently develop NFLE. ${ }^{61}$ Distinguishing NFE from nonepileptic parasomnias is sometimes difficult. The EEG may be nondiagnostic, but key features of NFLE and parasomnia are helpful for differentiation ${ }^{60}$ :

- NFLE seizures are frequent ( $>20 /$ month; $\geq 3 /$ night), NREM parasomnias are less frequent ( $<14 /$ month, 1-2/ night).

- NFLE often lasts $<2$ minutes and parasomnias seconds to 30 minutes.

- Movements are stereotyped and vigorous in NFLE and not highly stereotyped in parasomnias.

- Extrapyramidal symptoms, stiffening, dystonic posturing, or bipedal automatisms occur in NFLE but is very unusual in parasomnias.

- NFLE arise during stage 2 NREM sleep, parasomnias arise from slow-wave sleep.

- Recall of nocturnal events favors NFLE whereas absence of recollection is nondiagnostic.

Home videos and the application of "The Frontal Lobe Epilepsy and Parasomnias (FLEP)" scale may be helpful in differentiation, and video-EEG polysomnography is recommended when differentiation is not possible by history. ${ }^{60}$

\section{Influence of Sleep on Other Epilepsy Syndromes}

Absence epilepsies: Absence epilepsies are characterized by absence seizures and generalized 3/s spike waves. Seizures are only detectable when awake, but ISWs are most distinct in the first sleep cycle. During sleep, the ISW bursts become shorter and irregular and are intermixed with polyspikes, and focal spike waves may appear in the frontal regions.

Lennox-Gastaut syndrome: Lennox-Gastaut syndrome is characterized by tonic, tonic-clonic, myoclonic, and atypical absence seizures. Seizures are drug refractory and the patients mentally disabled. Tonic axial seizures frequently occur in sleep, although they are often subtle and detectable only in video-EEG recordings. Ictal EEG shows diffuse fast 10 to 20/s activity often preceded by attenuation of the background activity. The ictal discharges are usually brief and often without visible symptoms. Interictal EEG is characterized by generalized slow spike-wave complexes which increase during NREM sleep.

Temporal lobe epilepsy: Although in most patients seizures occur predominantly during wakefulness, ISW activity increases in frequency and extent during NREM sleep with maximum in stages 3 and 4 .

\section{Sleep and Sleep Deprivation in the Diagnostic of Epilepsy}

Sleep EEG recordings may be helpful in patients with suspected epilepsy and nonconclusive awake EEG. Depending on the clinical question, sleep recordings can be performed during nap (natural sleep or drug induced), during night, or after sleep deprivation. EEG in natural sleep is recommended in infants and easy to perform when the time schedule is carefully planned. Drug-induced nap EEGs are an option for patients with suspected epilepsy and nonconclusive wake EEG and for children with evidence of ESES/CSWS or LKS. Overnight EEG recordings should be performed when nap EEG is suspicious for ESES/CSWS or when frontal lobe epilepsy is suspected (video-EEG). Deprivation of sleep seems to be an independent activator of spike waves but is accompanied by a significant burden for patient and parents and bears the risk of an unintended seizure provocation. We use sleep deprivation very rarely, almost always in a hospital setting and only when JME is suspected or a patient's history and EEG are not conclusive.

The periods before falling asleep and after awakening may also contain useful information. EEG recordings after awakening are particularly recommended in patients with West syndrome (registration of infantile spasms) and JME (registration of generalized spike waves or myoclonic jerks).

\section{References}

1 Dinner DS, Lüders HO. Relationship of epilepsy and sleep: overview. In: Dinner DS, Lüders HO, eds. Epilepsy and sleep. Physiological and Clinical Relationships. San Diego, CA: Academic Press; 2001:2-18

2 Shewmon DW. Ictal aspects with emphasis on unusual variants. In: Dulac O, Chugani HT, Dalla Bernardina B, eds. Infantile Spasms and West Syndrome. London: WB Saunders Company; 1994: 36-51

3 Watanabe K, Negoro T, Aso K, Matsumoto A. Reappraisal of interictal electroencephalograms in infantile spasms. Epilepsia 1993;34(4):679-685

4 O'Callaghan FJ, Lux AL, Darke K, et al. The effect of lead time to treatment and of age of onset on developmental outcome at 4 years in infantile spasms: evidence from the United Kingdom Infantile Spasms Study. Epilepsia 2011;52(7):1359-1364

5 Rating D, Seidel U, Grimm B, Hanefeld F. The prognostic value of EEG patterns in epilepsies with infantile spasms. Brain Dev 1987; 9(4):361-364

6 Kramer U, Sue WC, Mikati MA. Hypsarrhythmia: frequency of variant patterns and correlation with etiology and outcome. Neurology 1997;48(1):197-203

7 Fattinger S, Schmitt B, Bölsterli Heinzle BK, Critelli H, Jenni OG, Huber R. Impaired slow wave sleep downscaling in patients with infantile spasms. Eur J Paediatr Neurol 2015;19(2): 134-142

8 Hancock EC, Osborne JP, Edwards SW. Treatment of infantile spasms. Cochrane Database Syst Rev 2013;6:CD001770

9 Go CY, Mackay MT, Weiss SK, et al; Child Neurology Society; American Academy of Neurology; Report of the Guideline Development Subcommittee of the American Academy of Neurology and the Practice Committee of the Child Neurology Society. Evidence-based guideline update: medical treatment of infantile spasms. Neurology 2012;78(24):1974-1980

10 Panayiotopoulos CP, Michael M, Sanders S, Valeta T, Koutroumanidis M. Benign childhood focal epilepsies: assessment of established and newly recognized syndromes. Brain 2008;131(Pt 9): 2264-2286

11 Specchio N, Trivisano M, Di Ciommo V, et al. Panayiotopoulos syndrome: a clinical, EEG, and neuropsychological study of 93 consecutive patients. Epilepsia 2010;51(10):2098-2107 
12 Koutroumanidis M, Ferrie CD, Valeta T, Sanders S, Michael M, Panayiotopoulos CP. Syncope-like epileptic seizures in Panayiotopoulos syndrome. Neurology 2012;79(5):463-467

13 Caraballo R, Cersósimo R, Fejerman N. Panayiotopoulos syndrome: a prospective study of 192 patients. Epilepsia 2007;48(6): 1054-1061

14 Specchio N, Trivisano M, Claps D, Battaglia D, Fusco L, Vigevano F. Documentation of autonomic seizures and autonomic status epilepticus with ictal EEG in Panayiotopoulos syndrome. Epilepsy Behav 2010;19(3):383-393

15 Lerman P. Benign partial epilepsy with centro-temporal spikes. In: Roger J, Dravet C, Bureau M, Dreifuss FE, Wolf P, eds. Epileptic Syndromes in Infancy, Childhood and Adolescence. London and Paris: John Libbey Eurotext Ltd; 1985:150-158

16 Commission on Classification and Terminology of the International League Against Epilepsy. Proposal for classification of epilepsies and epileptic syndromes. Epilepsia 1985;26(3):268-278

17 Loiseau P, Beaussart M. The seizures of benign childhood epilepsy with Rolandic paroxysmal discharges. Epilepsia 1973;14(4): 381-389

18 Eeg-Olofsson O. Rolandic epilepsy. In: Bazil CW, Malow BA, Sammaritano MR, eds. Sleep and Epilepsy: The Clinical Spectrum. Amsterdam: Elsevier; 2002:257-263

19 Glauser T, Ben-Menachem E, Bourgeois B, et al; ILAE Subcommission on AED Guidelines. Updated ILAE evidence review of antiepileptic drug efficacy and effectiveness as initial monotherapy for epileptic seizures and syndromes. Epilepsia 2013;54(3):551-563

20 Lerman P, Kivity S. Benign focal epilepsy of childhood. A follow-up study of 100 recovered patients. Arch Neurol 1975;32(4):261-264

21 Doose H, Baier WK. Benign partial epilepsy and related conditions: multifactorial pathogenesis with hereditary impairment of brain maturation. Eur J Pediatr 1989;149(3):152-158

22 Lemke JR, Lal D, Reinthaler EM, et al. Mutations in GRIN2A cause idiopathic focal epilepsy with rolandic spikes. Nat Genet 2013; 45(9):1067-1072

23 Nicolai J, van der Linden I, Arends JB, et al. EEG characteristics related to educational impairments in children with benign childhood epilepsy with centrotemporal spikes. Epilepsia 2007; 48(11):2093-2100

24 Binnie CD. Significance and management of transitory cognitive impairment due to subclinical EEG discharges in children. Brain Dev 1993;15(1):23-30

25 Patry G, Lyagoubi S, Tassinari CA. Subclinical "electrical status epilepticus" induced by sleep in children. A clinical and electroencephalographic study of six cases. Arch Neurol 1971;24(3): 242-252

26 Morikawa T, Seino M, Osawa T, Yagi K. Five children with continuous spike-wave discharges during sleep. In: Roger J, Dravet C, Bureau M, Dreifuss FE, Wolf P, eds. Epileptic Syndromes in Infancy, Childhood and Adolescence. London and Paris: John Libbey Eurotext Ltd; 1985:205-212

27 Carvill GL, Regan BM, Yendle SC, et al. GRIN2A mutations cause epilepsy-aphasia spectrum disorders. Nat Genet 2013;45(9): 1073-1076

28 Commission on Classification and Terminology of the International League Against Epilepsy. Proposal for revised classification of epilepsies and epileptic syndromes. Epilepsia 1989;30(4):389-399

29 Tassinari CA, Rubboli G, Volpi L, Billard C, Bureau M. Electrical status epilepticus during slow sleep (ESES or CSWS) including acquired epileptic aphasia (Landau-Kleffner syndrome). In: Roger J, Bureau M, Dravet C, Genton P, Tassinari CA, Wolf P, eds. Epileptic Syndromes in Infancy, Childhood and Adolescence. London and Paris: John Libbey Eurotext Ltd; 2005:295-314

30 Roulet Perez E, Davidoff V, Despland PA, Deonna T. Mental and behavioural deterioration of children with epilepsy and CSWS: acquired epileptic frontal syndrome. Dev Med Child Neurol 1993; 35(8):661-674
31 Galanopoulou AS, Bojko A, Lado F, Moshé SL. The spectrum of neuropsychiatric abnormalities associated with electrical status epilepticus in sleep. Brain Dev 2000;22(5):279-295

32 Schmitt B, Wohlrab G. EEG in der Neuropädiatrie. Berlin Heidelberg: Springer-Verlag; 2013

33 Scheltens-de Boer M. Guidelines for EEG in encephalopathy related to ESES/CSWS in children. Epilepsia 2009;50(Suppl 7):13-17

34 Aeby A, Poznanski N, Verheulpen D, Wetzburger C, Van Bogaert P. Levetiracetam efficacy in epileptic syndromes with continuous spikes and waves during slow sleep: experience in 12 cases. Epilepsia 2005;46(12):1937-1942

35 Guzzetta F, Battaglia D, Veredice C, et al. Early thalamic injury associated with epilepsy and continuous spike-wave during slow sleep. Epilepsia 2005;46(6):889-900

36 Bölsterli BK, Schmitt B, Bast T, et al. Impaired slow wave sleep downscaling in encephalopathy with status epilepticus during sleep (ESES). Clin Neurophysiol 2011;122(9):1779-1787

37 Bölsterli Heinzle BK, Fattinger S, Kurth S, et al. Spike wave location and density disturb sleep slow waves in patients with CSWS (continuous spike waves during sleep). Epilepsia 2014;55(4): 584-591

38 Siniatchkin M, Groening K, Moehring J, et al. Neuronal networks in children with continuous spikes and waves during slow sleep. Brain 2010;133(9):2798-2813

39 Veggiotti P, Pera MC, Teutonico F, Brazzo D, Balottin U, Tassinari CA. Therapy of encephalopathy with status epilepticus during sleep (ESES/CSWS syndrome): an update. Epileptic Disord 2012; 14(1):1-11

40 Pera MC, Brazzo D, Altieri N, Balottin U, Veggiotti P. Long-term evolution of neuropsychological competences in encephalopathy with status epilepticus during sleep: a variable prognosis. Epilepsia 2013;54(Suppl 7):77-85

41 Seegmüller C, Deonna T, Dubois CM, et al. Long-term outcome after cognitive and behavioral regression in nonlesional epilepsy with continuous spike-waves during slow-wave sleep. Epilepsia 2012;53(6):1067-1076

42 Aicardi J, Chevrie JJ. Atypical benign partial epilepsy of childhood. Dev Med Child Neurol 1982;24(3):281-292

43 Doose H. Symptomatology in children with focal sharp waves of genetic origin. Eur J Pediatr 1989;149(3):210-215

44 Hahn A. Atypical benign partial epilepsy/pseudo-Lennox syndrome. Epileptic Disord 2000;2(Suppl 1):S11-S17

45 Landau WM, Kleffner FR. Syndrome of acquired aphasia with convulsive disorder in children. Neurology 1957;7(8):523-530

46 Caraballo RH, Cejas N, Chamorro N, Kaltenmeier MC, Fortini S, Soprano AM. Landau-Kleffner syndrome: a study of 29 patients. Seizure 2014;23(2):98-104

47 Deonna TW. Acquired epileptiform aphasia in children (LandauKleffner syndrome). J Clin Neurophysiol 1991;8(3):288-298

48 Janz D, Christian W. Impulsiv-Petit mal. Dtsch Z Nervenheilkd 1957;176(3):346-386

49 Genton P, Thomas P, Kasteleijn-Nolst Trenité DG, Medina MT, Salas-Puig J. Clinical aspects of juvenile myoclonic epilepsy. Epilepsy Behav 2013;28(Suppl 1):S8-S14

50 Kasteleijn-Nolst Trenité DG, Schmitz B, Janz D, et al. Consensus on diagnosis and management of JME: From founder's observations to current trends. Epilepsy Behav 2013;28(Suppl 1):S87-S90

51 Mayer TA, Schroeder F, May TW, Wolf PT. Perioral reflex myoclonias: a controlled study in patients with JME and focal epilepsies. Epilepsia 2006;47(6):1059-1067

52 Thomas P, Genton P, Gelisse P, Wolf P. Juvenile myoclonic epilepsy. In: Roger J, Bureau M, Dravet C, Genton P, Tassinari CA, Wolf P, eds. Epileptic Syndromes in Infancy, Childhood and Adolescence. London and Paris: John Libbey Eurotext Ltd; 2005:367-388

53 Serafini A, Rubboli G, Gigli GL, Koutroumanidis M, Gelisse P. Neurophysiology of juvenile myoclonic epilepsy. Epilepsy Behav 2013;28(Suppl 1):S30-S39 
54 Schmitz B, Yacubian EM, Feucht M, Hermann B, Trimble M. Neuropsychology and behavior in juvenile myoclonic epilepsy. Epilepsy Behav 2013;28(Suppl 1):S72-S73

55 Crespel A, Gelisse P, Reed RC, et al. Management of juvenile myoclonic epilepsy. Epilepsy Behav 2013;28(Suppl 1):S81-S86

56 Senf P, Schmitz B, Holtkamp M, Janz D. Prognosis of juvenile myoclonic epilepsy 45 years after onset: seizure outcome and predictors. Neurology 2013;81(24):2128-2133

57 Janz D. Epilepsy with grand mal on awakening and sleep-waking cycle. Clin Neurophysiol 2000;111(Suppl 2):S103-S110

58 Genton P, Gonzales Sanchez M, Thomas P. Epilepsy with Grand Mal on awakening. In: Roger J, Bureau M, Dravet C, Genton P, Tassinari CA, Wolf $\mathrm{P}$, eds. Epileptic Syndromes in Infancy, Childhood and Adolescence. London and Paris: John Libbey Eurotext Ltd; 2005:389-394

59 Holtkamp M, Kowski AB, Merkle H, Janz D. Long-term outcome in epilepsy with grand mal on awakening: forty years of follow-up. Ann Neurol 2014;75(2):298-302
60 Derry CP. Sleeping in fits and starts: a practical guide to distinguishing nocturnal epilepsy from sleep disorders. Pract Neurol 2014;14(6):391-398

61 Provini F, Plazzi G, Tinuper P, Vandi S, Lugaresi E, Montagna P. Nocturnal frontal lobe epilepsy. A clinical and polygraphic overview of 100 consecutive cases. Brain 1999;122(Pt 6): 1017-1031

62 Scheffer IE, Bhatia KP, Lopes-Cendes I, et al. Autosomal dominant nocturnal frontal lobe epilepsy. A distinctive clinical disorder. Brain 1995;118(Pt 1):61-73

63 Heron SE, Smith KR, Bahlo M, et al. Missense mutations in the sodium-gated potassium channel gene KCNT1 cause severe autosomal dominant nocturnal frontal lobe epilepsy. Nat Genet 2012; 44(11):1188-1190

64 Picard F, Makrythanasis P, Navarro V, et al. DEPDC5 mutations in families presenting as autosomal dominant nocturnal frontal lobe epilepsy. Neurology 2014;82(23):2101-2106 